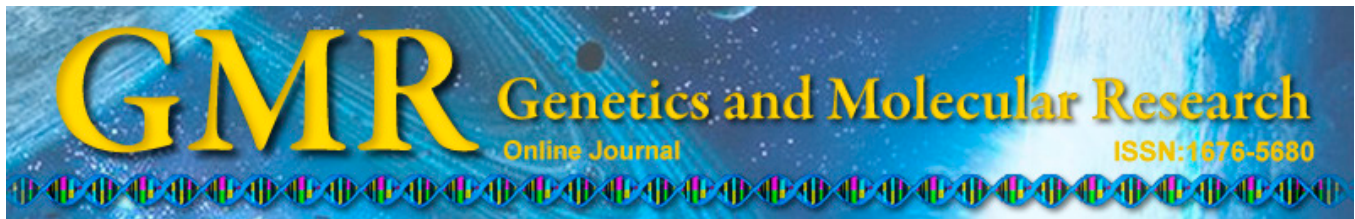

\title{
Determining the role of a probiotic in the restoration of intestinal microbial balance by molecular and cultural techniques
}

\author{
Affhan Shoaib, W. Dachang and Y. Xin \\ Department of Biotechnology, Dalian Medical University, Dalian, China \\ Corresponding author: Y. Xin \\ E-mail: jimxin@hotmail.com
}

Genet. Mol. Res. 14 (1): 1526-1537 (2015)

Received April 29, 2014

Accepted November 12, 2014

Published February 20, 2015

DOI http://dx.doi.org/10.4238/2015.February.20.8

\begin{abstract}
The human intestine has a vast variety of microorganisms, and their balance is dependent on several factors. Antibiotics affect microfloral balance and allow naturally opportunistic organisms to multiply. Azithromycin is the most widely used macrolide antibiotic, active against a wide number of pathogens including Pseudomonas aeruginosa and Staphylococcus aureus. It is currently used in the treatment of cystic fibrosis patients. The use of probiotics has advantages in gastrointestinal conditions, including infectious diarrhea and imbalance due to antibiotic use. In this research, the effect of azithromycin on the intestinal microbiota of Sprague Dawley rats and the role of Lactobacillus acidophilus in the restoration of the balance by employing molecular and cultural techniques was investigated. PCR with universal primers targeting the V3 region of the $16 \mathrm{~S}$ rRNA gene followed by DGGE was used to characterize the overall intestinal microbiota composition. Cultivable fecal bacteria count using microbiological media and semi-quantitative PCR with groupspecific primers were also utilized to analyze the effects of antibiotic and probiotic on microflora. We found that the total amount of $16 \mathrm{~S}$ rRNA gene and fecal aerobic bacterial count was reduced following
\end{abstract}


azithromycin administration along with elimination of non-pathogenic Escherichia coli, but it was restored by the use of the probiotic. The results from PCR with group-specific primers showed that Bacteroides sp was present in the control and probiotic groups, but it was nearly eliminated in the antibiotic group. Moreover, semi-quantitative PCR revealed that the numbers of Enterobacteriaceae were nearly the same in the probiotic group and decreased in the antibiotic group, while Bifidobacterium was significantly increased in the probiotic group and decreased in the antibiotic group $(\mathrm{P}<0.05)$ as compared with that in the control group. Azithromycin-induced dysbiosis can result in prolonged deleterious effects on the host. The present study revealed that the use of lactic acid bacteria particularly L. acidophilus helped to restore intestinal microfloral balance.

Key words: Intestinal microflora; Azithromycin; Polymerase chain reaction-denaturing gradient gel electrophoresis (PCR-DGGE); Lactobacillus acidophilus

\section{INTRODUCTION}

In the past decade there has been an increased interest in the study of intestinal microbial balance. The intestinal microbiota plays important roles such as maturation of the immune system (Mazmanian et al., 2005) and intestinal response to epithelial cell injury (RakoffNahoum et al., 2004). The human intestine has vast a variety of microorganisms (Gill et al., 2006), and their balance is dependent on several factors such as gastric acidity, gut motility, bile salts, colonic $\mathrm{pH}$, and competition between microorganisms for nutrients and intestinal binding sites (Marshall, 1999). Their disturbance may cause a variety of diseases or abnormal physiological states.

Drug administration may cause disturbance of the gut microbiota (Clayton et al., 2006). It is believed that antibiotics can affect the intestinal microfloral balance (Sullivan et al., 2001) and allow naturally opportunistic organisms to grow and multiply. Antibiotic therapy produce some side effects in the host, including disturbance of the metabolism and absorption of vitamins, alteration of susceptibility to infections (Levy, 2000), and overgrowth of yeast and/or Clostridium difficile (Sullivan et al., 2001).

Azithromycin (deoxo-azamethyl-homo-erythromycin, AZM) is the most widely used synthetic analogue having antimicrobiological properties (Mazzei et al., 1993). It is active against a wide number of pathogens including Streptococci, Staphylococcus aureus, Propionibacterium acnes, Listeria monocytogenes, Haemophilus influenzae, Neisseria gonorrhoeae, Mycobacterium avium, and Chlamydia trachomatis. AZM belongs to the macrolide antibiotics and is currently widely used in the treatment of cystic fibrosis patients (Jaffe et al., 1998). It is currently recommended as chronic therapy for cystic fibrosis patients infected with Pseudomonas aeruginosa (Southern et al., 2004; Flume et al., 2007). Long-term administration of AZM helps to reduce or stabilize clinical symptoms of airway inflammation in patients chronically infected with $P$. aeruginosa (Equi et al., 2002; Wolter et al., 2002; Saiman et al., 2003). Some side effects are associated with this macrolide therapy. One study has reported a significant increase in mild adverse effects (wheezing, diarrhea and nausea) in patients receiv- 
ing azithromycin (Saiman et al., 2003).

The use of probiotics has advantages in gastrointestinal conditions, including infectious diarrhea and imbalance due to antibiotic use (Sullivan and Nord, 2005). Probiotics are live microorganisms, which when administered in certain numbers exert health benefits in the host. They reduce the incidence of common infectious diseases (Weizman et al., 2005) and produce antipathogenic effects on extraintestinal sites (Peral et al., 2009), such as the vaginal tract (Martinez et al., 2009) and stomach (Park et al., 2007). They play a role in keeping the gut microbial ecosystem stable by restoring normal microflora (Erickson and Hubbard, 2000; Isolauri et al., 2001; Macfarlane and Cummings, 2002) and also take part in the removal of carcinogens, decreasing cholesterol and enhancing the availability of nutrients (Parvez et al., 2006). Currently Lactobacillus and Bifidobacterium species are attracting great interest as health supplements from both consumers and researchers because of increased awareness of their beneficial roles in health and nutrition (Stanton et al., 2001).

Recent advancements in molecular analysis of bacterial species have provided new tools to discover a highly diverse intestinal ecosystem (Tannock, 2001). Polymerase chain reaction together with denaturing gradient gel electrophoresis (PCR-DGGE) is one of the powerful techniques used for the exploration of the vast variety of microorganisms (Muyzer et al., 1993), and it is used to study their structure and evolution from the gastrointestinal tract (Zoetendal et al., 2002). This technique is useful for analyzing the bacterial diversity profile in different disease conditions (Liu et al., 2010). DGGE is applied to identify sequence variations in a number of genes (Muyzer et al., 1993) and 50\% of the sequence variants can be detected in DNA fragments up to $500 \mathrm{bp}$ (Myers et al., 1985). By the attachment of a GC clamp to one end of the DNA fragment, this percentage can be increased to nearly $100 \%$ (Sheffield et al., 1989).

This study aimed to demonstrate the effect of AZM on the intestinal microbial ecosystem and the role of Lactobacillus acidophilus in intestinal microbial balance by employing molecular and cultural techniques, since there is a correlation between molecular and cultural measurements when individual species are measured. Deviation is due to picking up DNA from non-viable cells by molecular techniques.

\section{MATERIAL AND METHODS}

\section{Animals and treatments}

Twenty-four male Sprague Dawley rats (weighing $200 \pm 2$ g) of SPF grade were supplied by the Animal Lab Center of Dalian Medical University. All rats were housed in a standard facility, allowed unrestricted access to water and food and distributed into three groups: control, antibiotic-administered and antibiotic followed by probiotic. AZM was given at 200 $\mathrm{mg} / \mathrm{kg}$ to the antibiotic and probiotic groups for 7 days. After antibiotic administration, L. acidophilus $878\left(1 \times 10^{9} \mathrm{CFU} /\right.$ day $)$ was administered to probiotic group for 7 days. L. acidophilus 878 was provided by China Medical Culture Collection (CMCC). Drug and probiotic were given by gavage $(0.2 \mathrm{~mL})$. Average body weight of all groups was also calculated to check the effects of antibiotic and probiotic. Luria-Bertani (LB), MacConkey's, eosine methylene blue (EMB), de Mann Rogosa Sharpe (MRS), and sorbitol MacConkey's (SMAC) agar were used for microbial culture techniques. 


\section{DNA isolation}

Fecal samples were collected from each rat in each group after 7 days following antibiotic course and at the end of the probiotic administration period and stored at $-80^{\circ} \mathrm{C}$ until analysis, and total bacterial DNA was extracted by using E.Z.N.A. Stool DNA kit (OMEGA, USA), according to the manufacturer protocol. DNA integrity was determined visually after electrophoresis on a $1 \%$ agarose gel containing ethidium bromide. DNA concentration was measured spectrophotometrically using BioPhotometer plus (NanoVue, USA). Extracted DNA samples were stored at $-20^{\circ} \mathrm{C}$.

\section{PCR amplification}

Primers targeting the V3 region of bacterial 16S rRNA (TaKaRa Biotechnology Co., Ltd., Japan) were used for PCR amplification as shown in Table 1. An automated thermocycler (Thermo USA) was used to perform PCR amplification using a $50-\mu \mathrm{L}$ reaction mixture containing $2 \mu \mathrm{L}$ template genomic DNA, $5 \mu \mathrm{L}$ 10X ExTaq buffer ( $\mathrm{Mg}^{2+}$ plus), $8 \mu \mathrm{L}$ dNTP mixture, $5 \mu \mathrm{L}$ $1 \% \mathrm{BSA}, 1 \mu \mathrm{L} 10 \mathrm{pmol}$ of each primer, $0.5 \mu \mathrm{L} 1.25 \mathrm{U}$ ExTaq polymerase (TaKaRa), and sterile Milli-Q water to volume. PCR program was as follows: $94^{\circ} \mathrm{C}$ for $5 \mathrm{~min} ; 30$ cycles of $94^{\circ} \mathrm{C}$ for 30 $\mathrm{s}, 54^{\circ} \mathrm{C}$ for $30 \mathrm{~s}$, and $72^{\circ} \mathrm{C}$ for $30 \mathrm{~s}$; and finally, $72^{\circ} \mathrm{C}$ for $7 \mathrm{~min}$. The PCR products were evaluated by $2 \%$ agarose gel electrophoresis containing ethidium bromide at $100 \mathrm{~V}$ for $45 \mathrm{~min}$.

\begin{tabular}{ll}
\multicolumn{2}{c}{ Table 1. Primers targeting V3 region of bacterial 16S rRNA. } \\
\hline F-primer & 5'-GC clamp- CCTACGGGAGGCAGCAG-3' \\
R-primer & 5'-ATT ACC GCG GCT GCT GG-3' \\
GC clamp & CGC CCG GGG CGC GCC CCG GGC GGG GCG GGG GCA CGG GGG G \\
\hline
\end{tabular}

\section{DGGE}

DGGE was performed on D-Code ${ }^{\mathrm{TM}}$ Universal Mutation Detection System (Bio-Rad, Hercules, CA, USA). Briefly, PCR products were loaded on $8 \%$ polyacrylamide gel containing $35-55 \%$ gradient of urea and formamide. Electrophoresis was performed, first for $10 \mathrm{~min}$ at $200 \mathrm{~V}$, and subsequently for $16 \mathrm{~h}$ at $70 \mathrm{~V}$ in a $1 \mathrm{X}$ TAE buffer at a constant temperature of $60^{\circ} \mathrm{C}$. The gels were stained with $0.5 \mu \mathrm{g} / \mathrm{mL}$ ethidium bromide for $60 \mathrm{~min}$, washed with deionized water, and viewed with a Gel Documentation System (Bio-Rad).

\section{DGGE analysis}

DGGE profiles were analyzed by the Phoretix 1D software (Phoretix, Newcastle upon Tyne, USA). The similarity score and clustering were determined using the unweighted pair group method with arithmetic averages (UPGMA). The analysis was performed by the SPSS software version 11.5. The Shannon-Weaver diversity index $\left(\mathrm{H}^{\prime}\right)$ was computed to determine the intestinal microbial diversity by the formula:

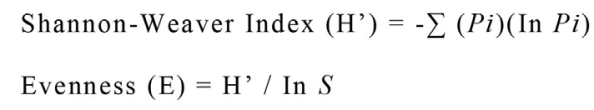

(Equation 1) 
where $P i=$ proportion of bands/species in the sample and $S=$ number of bands.

\section{Sequence analysis}

Selected bands were excised from the gel with a sterile scalpel, washed with deionized water and incubated in $35 \mu \mathrm{L}$ TE buffer at $4^{\circ} \mathrm{C}$ overnight. The extracted gel mix was heated at $90^{\circ} \mathrm{C}$ for $10 \mathrm{~min}$, and $4 \mu \mathrm{L}$ of the solution served as the template for PCR re-amplifying by using the same set of primers and programs described previously but without GC clamp. PCR products were electrophoresed on a $\%$ agarose gel, purified and then cloned into the PMD19T Easy vector (TaKaRa), transformed into competent Escherichia coli Nova blue cells, and screened for positive plasmid insertions according to the manufacturer protocol. Plasmid DNA was extracted from positive clones, amplified by PCR and sent for sequencing (TaKaRa).

\section{Semi-quantitative PCR}

The genus Bacteroides, Enterobacteriaceae and Bifidobacterium were semi-quantified by using group-specific primers as shown in Table 2. An automated thermocycler (Thermo USA) was used to perform semi-quantitative PCR. Each $25-\mu \mathrm{L}$ reaction mixture contained $1 \mu \mathrm{L}$ template, $2.5 \mu \mathrm{L}$ 10X ExTaq buffer, $4 \mu \mathrm{L}$ dNTP mixture, $2.5 \mu \mathrm{L} 1 \% \mathrm{BSA}, 1 \mu \mathrm{L}$ of each primer, and $2.5 \mathrm{U}$ ExTaq polymerase (TaKaRa). For Enterobacteriaceae, the amplification program was set as $95^{\circ} \mathrm{C}$ for $1 \mathrm{~min}$, then 40 cycles of $95^{\circ} \mathrm{C}$ for $5 \mathrm{~s}, 55^{\circ} \mathrm{C}$ for $30 \mathrm{~s}$, and $72^{\circ} \mathrm{C}$ for $30 \mathrm{~s}$, and finally $72^{\circ} \mathrm{C}$ for $7 \mathrm{~min}$. For Bifidobacterium, the program was set as $95^{\circ} \mathrm{C}$ for 1 min, then 40 cycles of $95^{\circ} \mathrm{C}$ for $10 \mathrm{~s}, 55^{\circ} \mathrm{C}$ for $15 \mathrm{~s}$, and $72^{\circ} \mathrm{C}$ for $50 \mathrm{~s}$, and finally $72^{\circ} \mathrm{C}$ for 7 $\mathrm{min}$. The PCR products were evaluated by $2 \%$ agarose gel electrophoresis and semi-quantified by using Gel Pro Analyzer 4.0. PCR with group-specific primers targeting Bacteroides sp was also performed to check the presence of Bacteroides sp in all three groups as follows: $94^{\circ} \mathrm{C}$ for $5 \mathrm{~min}$, followed by 40 cycles of $94^{\circ} \mathrm{C}$ for $20 \mathrm{~s}, 55^{\circ} \mathrm{C}$ for $20 \mathrm{~s}$, and $72^{\circ} \mathrm{C}$ for $30 \mathrm{~s}$. All samples were assayed simultaneously in three parallel reactions.

Table 2. Group specific primers targeting $16 \mathrm{~S}$ rRNA used in semi-quantitative PCR.

\begin{tabular}{lll}
\hline Genus & Primer & Sequence (5'-3') \\
\hline Enterobacteriaceae & Ecol-F & CATTGACGTTACCCGCAGAAGAAGC \\
Bifidobacterium & Ecol-R & CTCTACGAGACTCAAGCTTGC \\
Bacteroides & Bifid-F & CTCCTGGAAACGGGTGG \\
& Bifid-R & GGTGTTCTTCCCGATATCTACA \\
& Bact-F & GGTTCTGAGAGGAGGTCCC \\
\hline
\end{tabular}

\section{Bacterial culture of feces and identification of predominant bacteria}

Standard plate count was performed for the cultivation of aerobic, enteric, coliform, and lactic acid bacteria from fresh fecal samples. Briefly, $1 \mathrm{~g}$ fecal samples from each group was serially diluted and seeded onto LB agar (for aerobes), MacConkey's agar (for Enterobacteriaceae) and MRS agar (for lactic acid bacteria). All plates were incubated for 24-48 h at $37^{\circ} \mathrm{C}$. Isolated colonies from MacConkey's agar were streaked onto EMB and SMAC agar for the identification of bacteria. All samples were assayed in duplicate. 


\section{RESULTS}

\section{DGGE analysis}

The intestinal microbial diversity from control, antibiotic and probiotic groups was analyzed to compare the $\mathrm{H}^{\prime}$ of the bands from the DGGE profile. Number of bands significantly decreased $(\mathrm{P}<0.05)$ in the antibiotic group as compared to control and probiotic groups as indicated in Table 3 .

For sequencing in the DGGE, clear and selected bands were cut from the gel based on quantity analysis. Bands in the same position but in different lanes were excised and sequenced to confirm that they had the same identity. As shown in Figure 1, the control and probiotic groups shared bands (Bands A) at the same position, while there was nearly no band at the corresponding place from the antibiotic group, revealing microbial disturbances. Unfortunately, we could not determine the sequence of selected bands. So we decided to go for PCR using group-specific primers.

A dendrogram was constructed from DGGE profiles using the Phoretix 1D software. Figure 2 illustrates that two clusters were formed. Cluster 1 contained the control and probiotic groups, while in cluster 2, there were two subclusters: subcluster 1 related to the antibiotic group and subcluster 2 related to the probiotic group.

Table 3. Microbial diversity index analysis (means $\pm \mathrm{SD}$ ).

\begin{tabular}{lccc}
\hline Parameters & Normal group & Antibiotic group & Probiotic group \\
\hline Number of bands & $7.0 \pm 2.0$ & $3.50 \pm 0.57^{*}$ & $5.50 \pm 2.3$ \\
Shannon-Weaver index $\left(\mathrm{H}^{\prime}\right)$ & $1.75 \pm 0.59$ & $1.07 \pm 0.16$ & $1.46 \pm 0.74$ \\
Evenness $(\mathrm{E})$ & $0.89 \pm 0.18$ & $0.86 \pm 0.07$ & $0.85 \pm 0.21$ \\
\hline
\end{tabular}

$*$ P value $<0.05$ ( $t$-test) considered statistically significant.

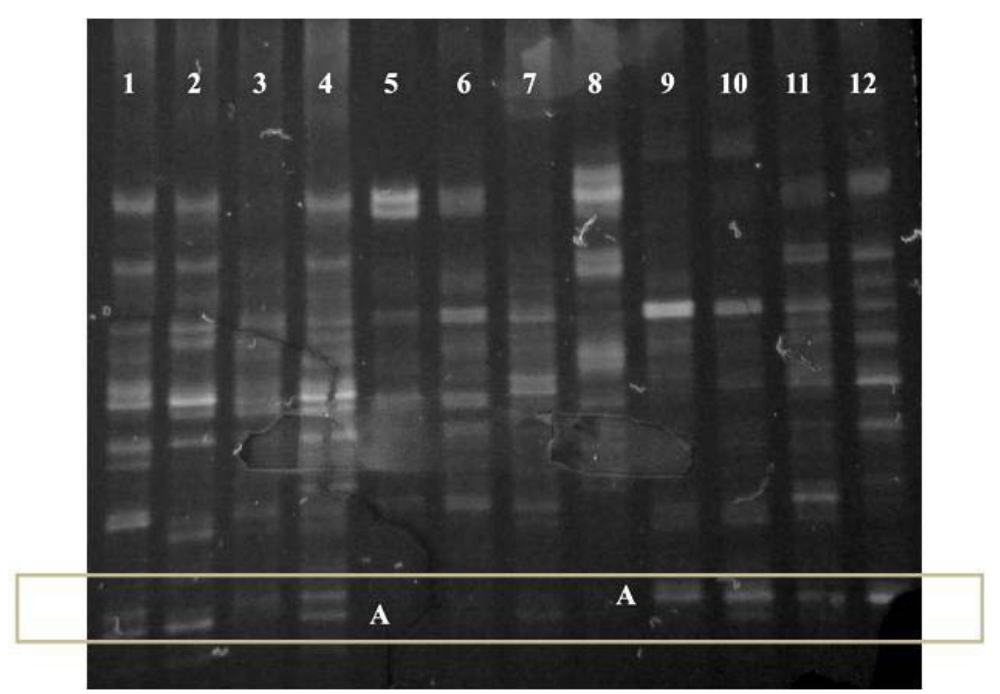

Figure 1. Denaturing gradient gel electrophoresis. Lanes $1-4=$ control group, lanes 5-8 = antibiotic group, lanes 9-12 $=$ probiotic group. 


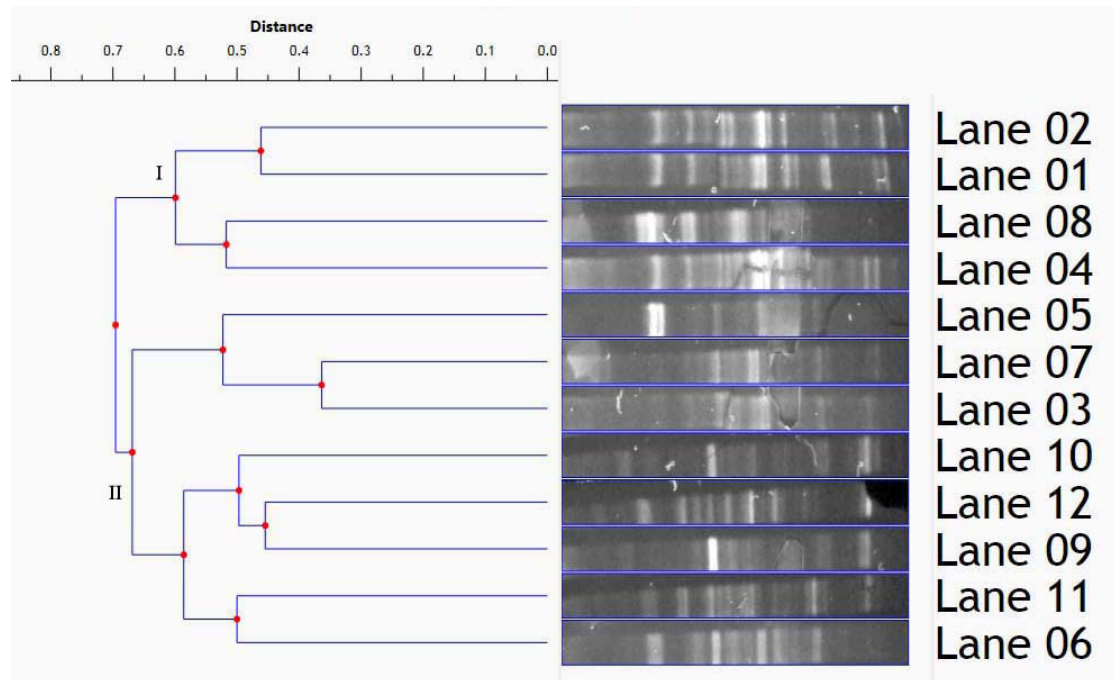

Figure 2. Dendogram of DGGE profiles analyzed by UPGMA. Lanes $1-4=$ control group, lanes 5-8 = antibiotic group, lanes $9-12=$ probiotic group.

\section{Semi-quantitative PCR}

Enterobacteriaceae, Bifidobacterium and Bacteroides are the most important bacterial groups in the intestine, and they were identified by PCR with group-specific primers (Figures 3-5). Enterobacteriaceae were nearly the same in the probiotic group and decreased in the antibiotic group, while Bifidobacterium was significantly increased in the probiotic group and decreased in the antibiotic group $(\mathrm{P}<0.05)$ as compared with the control group (Table 4$)$. $B i$ fidobacterium to Enterobacteriaceae $(\mathrm{B} / \mathrm{E})$ ratio is a sign of microbial colonization resistance in the gut. This ratio was lower in the antibiotic group than that in the control and probiotic groups. As shown in Figure 4, the control and probiotic groups indicated the presence of Bacteroides sp in the fecal samples, while AZM produced a deleterious effect on this group of bacteria.

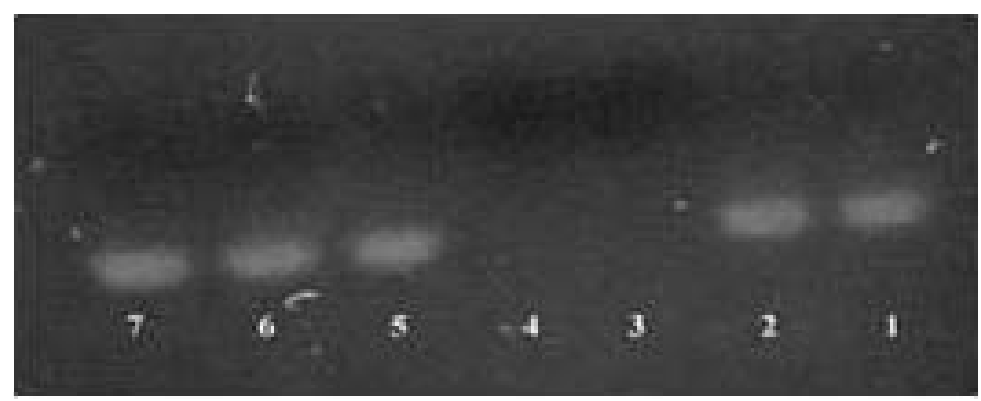

Figure 3. PCR using Bacteroides group specific primers. Lanes 1-2 = control group, lanes 3-4 = antibiotic group, lanes $5-7=$ probiotic group. 


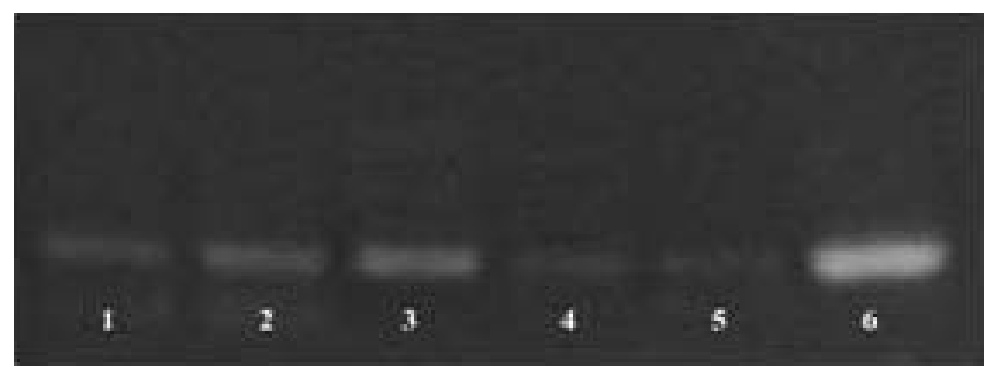

Figure 4. Semi-quantitative PCR using Bifidobacterium group specific primers. Lanes $1-3=$ probiotic group, lanes 4-5 = antibiotic group, lane $6=$ control group.

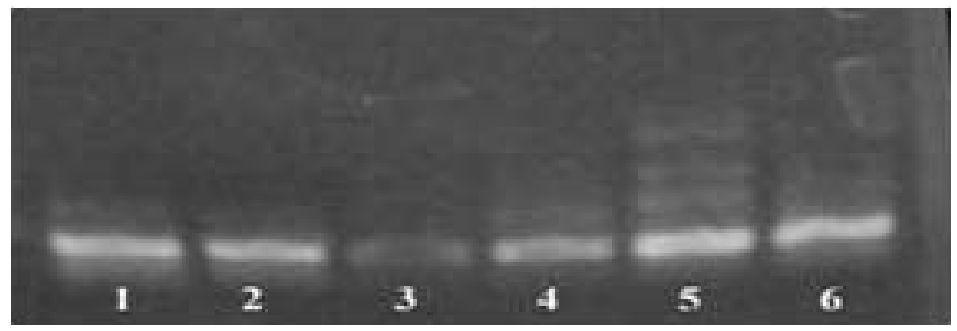

Figure 5. Semi-quantitative PCR using Enterobacteriaceae group specific primers. Lanes $1-2=$ probiotic group, lanes 3-4 = antibiotic group, lanes 5-6= control group.

Table 4. Semi-quantitative PCR analysis of bacterial population (means \pm SD).

\begin{tabular}{lccc}
\hline Bacterial genus & Control group & Antibiotic group & Probiotic group \\
\hline Enterobacteriaceae & $6.39 \pm 0.65$ & $3.55 \pm 0.65$ & $5.50 \pm 0.06^{*}$ \\
Bifidobacterium & $5.79 \pm 0.17$ & $1.73 \pm 0.03^{*}$ & $2.97 \pm 0.03^{*}$ \\
\hline
\end{tabular}

$* \mathrm{P}$ value $<0.05$ ( $t$-test) considered statistically significant.

\section{Bacterial culture of feces and identification of predominant bacteria}

Figure 6 illustrates the average body weight of rats, and Figure 7 shows the log CFU/g values for fecal aerobic, enteric, coliform, and lactic acid bacterial counts in all three groups. AZM therapy reduced the number of aerobic, enteric, and particularly lactose-fermenting bacteria, as well as body weight, indicating a detrimental impact on the host microbial ecosystem. While probiotic therapy restored intestinal balance and increased the counts of aerobic, enteric and lactic acid bacteria. E. coli was dominant in the control and probiotic groups but not in the AZM-administered group according to bacterial culture of fecal samples onto MacConkey's and EMB agar. It produced lactose-fermenting pink and greenish metallic sheen colonies on respective agar plates. The API 20E identification scheme was also utilized to confirm isolated bacteria. Sorbitol-fermenting E. coli colonies on SMAC agar confirmed the presence of nonpathogenic strain in the control and probiotic groups. Lactic acid bacterial count was higher in 
the probiotic group as compared with that in the control and antibiotic groups indicating the beneficial role of the probiotic in the gut.

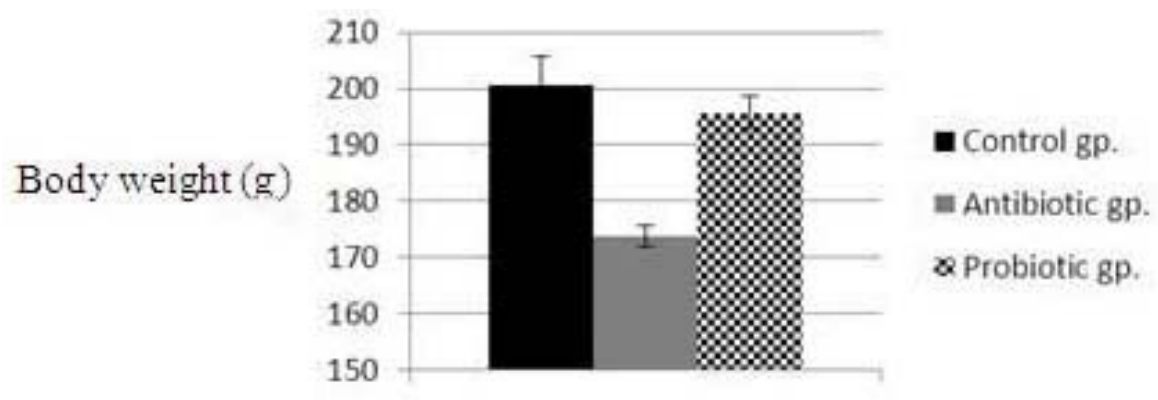

Figure 6. Average body weight of rats during study.

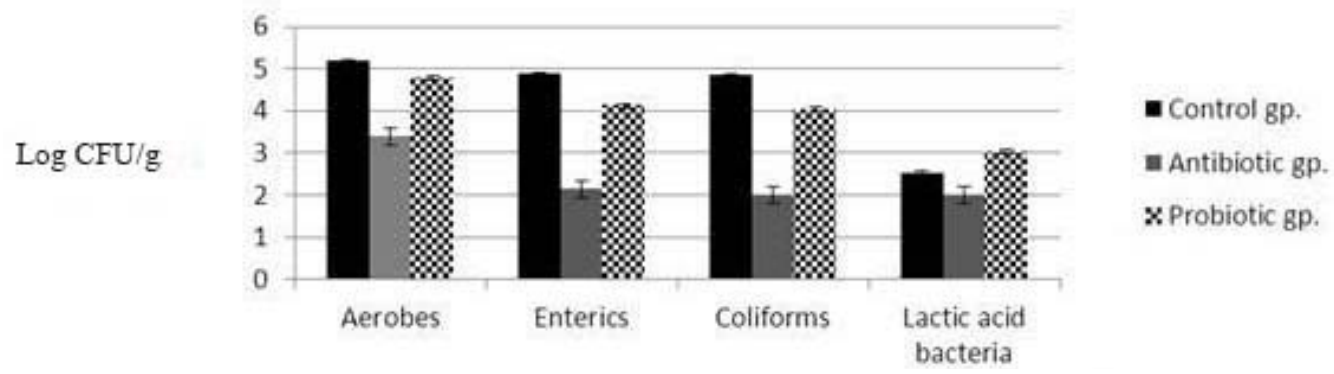

Figure 7. Bacterial culture of feces using different bacteriological media.

\section{DISCUSSION}

Culturing of microorganism is the gold standard technique in the field of microbiology, but it fails to represent the complete information of intestinal microflora which comprises many non-cultivable bacteria. In contrast, molecular methods based on the direct analysis of environmental DNA without any culture step have been developed to study microbial communities. Among these methods, PCR-DGGE and PCR-temporal temperature gradient gel electrophoresis (Muyzer et al., 1993) have been widely used for profiling environmental or food-associated microbial ecosystems. Bands excised from the gels and sequenced to get taxonomic identity is the most important feature of DGGE. In the current study, we assessed the potential of $L$. acidophilus as it is widely used in the preparation of probiotic-supplemented food products. Bile acid tolerance makes this bacterium a better candidate to establish its colony in the gut. This bacterium inhibits the colonization of pathogens by increased IgA production (Perdigon et al., 1995). L. acidophilus CMCC 878 is an authorized representative strain of this species.

The qualitative composition of intestinal microbiota from each group was analyzed by DGGE with universal primers. DGGE profiles showed the typical characteristics of general bacteria in the intestine. Each band derived possibly from one phylogenetically distinct community; hence, an estimation of species number could be based on the total number of the bands in the profile (Hu et al., 2007). Number of bands and intestinal microbial diversity 
of the AZM-administered group were lower than that of the control and probiotic groups. A previous study reported that the administration of antibiotics may cause disturbance of the gut microbiota (Clayton et al., 2006). This allows natural opportunists to grow and increase their population. AZM is widely used for the treatment of bacterial lung infections in patients with cystic fibrosis. The current study demonstrated the possible side effects of this antibiotic on the gut microbial ecosystem.

According to PCR with group-specific primers, Bacteroides sp was identified in the control and probiotic groups, but AZM administration nearly eliminated Bacteroides sp, indicating antibiotic-induced intestinal imbalance and the restoration of microbial balance by probiotic use. Bacteroides sp improves human health by improving the efficiency of nutrition (Bäckhed et al., 2004), increasing the vascularization of the gut mucosa (Stappenbeck et al., 2002), and maintaining the intestinal microbial balance (Hooper et al., 2001; Sears, 2005). A previous study has shown that probiotics improve the ecology of intestinal microbiota (Barrow, 1992). Probiotics have been used to provide health benefits to the host by enhancing the growth of beneficial intestinal bacteria (Rastall et al., 2005). Decreased Bacteroides sp with antibiotic administration is associated with side effects in the intestinal tract. The result is in agreement with those obtained in a previous study that indicated a decrease in Bacteroides sp in the intestine of macrolide antibiotic-treated mice (Li et al., 2013).

PCR with group-specific primers is considered to be a precise and sensitive method for accurate quantification of individual species. In this study, semi-quantitative PCR also revealed the deleterious effects of AZM on gut ecology and restoration of this balance by probiotic therapy. Enterobacteriaceae were nearly the same in the probiotic-fed group and reduced in antibiotic-administered group as compared with the control group, while AZM significantly decreased and probiotic significantly increased Bifidobacterium as compared with the control group. Emmelot and Van der Waaij in 1980 found that oral doses of neomycin and polymyxin B eliminated Enterobacteriaceae in conventional mice. Enterobacteriaceae are the group of Gram-negative enteric bacteria consisting of normal, pathogenic and opportunistic organisms while the Bifidobacterium group is considered probiotics and provide protection against different gut infections. They also restore the normal intestinal flora during antibiotic therapy.

To ascertain that the antibiotic induced intestinal dysbiosis, fecal aerobic bacterial count was evaluated, which was lower in the antibiotic group than that in the control and probiotic groups. Lactose-fermenting bacterial colonies on MacConkey's agar were nearly the same in the control and probiotic groups. Predominant bacteria were isolated and identified as a non-pathogenic strain of E. coli. But this bacterial strain was absent in the AZMadministered group. E. coli is a normal gut inhabitant and provides different benefits to the host, including synthesis of vitamin K. Some strains of E. coli (such as E. coli O157:H7) are pathogenic, unable to ferment sorbitol and form colorless colonies on SMAC agar.

\section{CONCLUSION}

Minimal disruption in the intestinal microbiota by AZM can result in prolonged injurious effects on the ability of the host to resist infections. The present study revealed that the use of lactic acid bacteria, particularly L. acidophilus, helps to restore intestinal microbial balance. L. acidophilus as a probiotic could be the best candidate to treat gut infections because of their additional ability to tolerate bile acids. Additional studies are necessary to determine the potential of these bacteria to restrict the growth and colonization of opportunistic and 
pathogenic bacteria.

\section{Conflicts of interest}

The authors declare no conflict of interest.

\section{ACKNOWLEDGMENTS}

Research supported by the National Basic Research Program of China with a "973" project (\#2007CB513006).

\section{REFERENCES}

Bäckhed F, Ding H, Wang T, Hooper LV, et al. (2004). The gut microbiota as an environmental factor that regulates fat storage. Proc. Natl. Acad. Sci. U. S. A. 101: 15718-15723.

Barrow P (1992). Probiotics for chickens [M]. Fuller R. Probiotics, the scientific basis. London: Chapman \& Hall. pp. 225-257.

Clayton TA, Lindon JC, Cloarec O, Antti H, et al. (2006). Pharmaco-metabonomic phenotyping and personalized drug treatment. Nature 440: 1073-1077.

Emmelot CH and Van Der Waaij D (1980). The dose at which neomycin and polymyxin B can be applied for selective decontamination of the digestive tract in mice. J. Hyg. 69: 83-89.

Equi A, Balfour-Lynn IM, Bush A, Rosenthal M, et al. (2002). Long term azithromycin in children with cystic fibrosis: a randomised, placebo-controlled crossover trial. Lancet 360: 978-984.

Erickson KL and Hubbard NE (2000). Probiotic immunomodulation in health and disease. J. Nutr. 130: S403-409.

Flume PA, Sullivan BP, Robinson KA, Goss CH, et al. (2007). Cystic Fibrosis Foundation, Pulmonary Therapies Committee. Cystic fibrosis pulmonary guidelines: chronic medications for maintenance of lung health. Am. J. Respir. Crit. Care. Med. 176: 957-969.

Gill SR, Pop M, Deboy RT, Eckburg PB, et al. (2006). Metagenomic analysis of the human distal gut microbiome. Science 312: $1355-1359$.

Hooper LV, Wong MH, Thelin A, Hansson L, et al. (2001). Molecular analysis of commensal host-microbial relationships in the intestine. Science 291: 881-885.

Hu Q, Qi HY, Zeng JH and Zhang HX (2007). Bacterial diversity in soils around a lead and zinc mine. J. Environ. Sci. 19: 74-79.

Isolauri E, Sutas Y, Kankaanpaa P, Arvilommi H, et al. (2001). Probiotics: effects on immunity. Am. J. Clin. Nutr. 73: S444-550.

Jaffe A, Francis J, Rosenthal M, Bush A, et al. (1998). Long-term azithromycin may improve lung function in children with cystic fibrosis. Lancet 351-420.

Levy J (2000). The effects of antibiotic use on gastrointestinal function. Am. J. Gastroenterol. 95: S8-S10.

Li XL, Liu J, Wu DC, Zhang CL, et al. (2013). Detection of intestinal microflora from mice affected by macrolide antibiotics. Afr. J. Microbiol. Res. 7: 1475-1479.

Liu DL, Zhou YB, Li CL, Li YP et al. (2010). Denaturing gradient gel electrophoresis analysis of subgingival bacterial communities under mechanical debridement with different primers. Microbiol. Immunol. 54: 702-706.

Macfarlane GT and Cummings JH (2002). Probiotics, infection and immunity. Curr. Opin. Infect. Dis. 15: 1-6.

Marshall JC (1999). Gastrointestinal flora and its alterations in critical illness. Curr. Opin. Clin. Nutr. 2: 405-411.

Martinez RC, Franceschini SA, Patta MC, Quintana SM et al. (2009). Improved cure of bacterial vaginosis with single dose of tinidazole (2 g), Lactobacillus rhamnosus GR-1, and Lactobacillus reuteri RC-14: a randomized, doubleblind, placebo-controlled trial. Can. J. Microbiol. 55; 133-138.

Mazmanian SK, Liu CH, Tzianabos AO and Kasper DL (2005). An immunomodulatory molecule of symbiotic bacteria directs maturation of the host immune system. Cell 122: 107-118.

Mazzei T, Mini E, Novelli A and Periti P (1993). Chemistry and mode of action of macrolides. J. Antimicrob. Chemother. 31 (Suppl C): 1-9.

Muyzer G, Dewaal EC and Uitterlinden AG (1993). Profiling of complex microbial populations by denaturing gradient gel electrophoresis analysis of polymerase chain reaction amplified genes-coding for 16S ribosomal RNA. Appl. 
Environ. Microbiol. 59: 695-700.

Myers RM, Fischer SG, Lerman LS and Maniatis T (1985). Nearly all single base substitutions in DNA fragments joined to a GC140 clamp can be detected by denaturing gradient gel electrophoresis. Nucleic Acids Res. 13: 3131-3145.

Park SK, Park DI, Choi JS, Kang MS, et al. (2007). The effect of probiotics on Helicobacter pylori eradication. Hepatogastroenterology 54: 2032-2036.

Parvez S, Malik KA, Ah Kang S and Kim HY (2006). Probiotics and their fermented food products are beneficial for health. J. Appl. Microbiol. 100: 1171-1185.

Peral MC, Martinez MA and Valdez JC (2009). Bacteriotherapy with Lactobacillus plantarum in burns. Int. Wound J. 6: 73-81.

Perdigon G, Alvarez S, Rachid M, Aguero G, et al. (1995). Immune system stimulation by probiotics. J. Dairy Sci. 78: $1597-1606$.

Rakoff-Nahoum S, Paglino J, Eslami-Varzaneh F, Edberg S, et al. (2004). Recognition of commensal microflora by tolllike receptors is required for intestinal homeostasis. Cell 118: 229-241.

Rastall R, Gibson G, Gill H, Guarner F, et al. (2005). Modulation of the microbial ecology of the human colon by probiotics, prebiotics and synbiotics to enhance human health: an overview of enabling science and potential applications. FEMS Microbiol. Ecol. 52: 145-152.

Saiman L, Marshall BC, Mayer-Hamblett N, Burns JL, et al. (2003). Macrolide Study Group. Azithromycin in patients with cystic fibrosis chronically infected with Pseudomonas aeruginosa: a randomized controlled trial. JAMA 290: 1749-1756.

Sears CL (2005). A dynamic partnership: Celebrating our gut flora. Anaerobe 11: 247-251.

Sheffield VC, Cox DR and Myers RM (1989). Attachment of a 40-bp G+C rich sequence (GCclamp) to genomic DNA fragments by polymerase chain reaction results in improved detection of single-base changes. Proc. Natl. Acad. Sci. U. S. A. 86: 232-236.

Southern KW, Barker PM and Solis A (2004). Macrolide antibiotics for cystic fibrosis. Cochrane. Database. Syst. Rev. 2: CD002203.

Stanton C, Gardiner G, Meehan H, Collins K, et al. (2001). Market potential for probiotics. Am. J. Clin. Nutr. 73: 476S-483S.

Stappenbeck TS, Hooper LV and Gordon JI (2002). Developmental regulation of intestinal angiogenesis by indigenous microbes via paneth cells. Proc. Natl. Acad. Sci. U. S. A. 99: 15451-15455.

Sullivan A and Nord CE (2005). Probiotics and gastrointestinal diseases. J. Intern. Med. 257: 78-92.

Sullivan A, Edlund C and Nord CE (2001). Effect of antimicrobial agents on the ecological balance of human microflora. Lancet Infect. Dis. 1: 101-114.

Tannock GW (2001). Molecular assessment of intestinal microflora. Am. J. Clin. Nutr. 73: 410S-414S.

Weizman Z, Asli G and Alsheikh A (2005). Effect of a probiotic infant formula on infections in child care centers: comparison of two probiotic agents. Pediatrics 115: 5-9.

Wolter J, Seeney S, Bell S. Bowler S, et al. (2002). Effect of long term treatment with azithromycin on disease parameters in cystic fibrosis: a randomised trial. Thorax 57: 212-216.

Zoetendal EG, von Wright A, Vilpponen-Salmela T, Ben-Amor K, et al. (2002). Mucosaassociated bacteria in the human gastrointestinal tract are uniformly distributed along the colon and differ from the community recovered from feces. Appl. Environ. Microbiol. 68: 3401-3407. 